\title{
Are U.S. Farm Wages Really Depressing? Evidence from the Northeast and South
}

\author{
Tugrul Temel and Edmund M. Tavernier*
}

\begin{abstract}
This study examines movements in U.S. real farm wages and whether or not wages tend to converge during 1978-92. Results from the Markov chain analysis support convergence in both the Northeast and the South to a lower wage rate than their respective regional average rates in 1978. A comparison of the time-invariant and actual terminal period distributions indicates that such tendency signals future wages to depress. This further suggests that the oversupply of labor, which manifests itself in the form of lower wages, can be viewed as a symptom of a healthy labor market responding to market signals.
\end{abstract}

\section{INTRODUCTION}

The hired labor component of the farm workforce is perhaps the least understood and most controversial of farm inputs. A controversy centers around the supply of seasonal workers, which is highly dependent on non-U.S. citizens subject to U.S. immigration policies. Each year, farmers hire a large number of these workers for seasonal jobs, often complaining that labor supply is unpredictable and scarce when needed most. Advocates of farm operators argue that temporary foreign worker programs and tolerant entry programs at U.S. borders are necessary means of ensuring an affordable work force during critical periods. On the contrary, farm workers' organizations often contend that such policies create an oversupply of workers and depress wages. In conformity with the claims of workers' organizations, our long-run projection of wage distribution, based on actual movements in wages during the period 1978-92, suggests that it is indeed more likely for wages to reach an equilibrium at a level lower than the 1978 average wage rate.

With accelerated organizational changes in farming and increased costs of labor, the period 1978-92 represents a turning point for U.S. agriculture. Agriculture experienced a shift from family to corporate farming, with a 17 percent decline in the number of family and partnership farms and 45 and 36 percent increases in corporate and cooperative farms, respectively (U.S. Department of Commerce 1992). Often occupying the first seat in debates, this shift worried policy makers most since it signaled structural changes and called for the design and implementation of new regulations. The second seat was occupied by continuously rising costs of labor, with a 90 percent increase in labor cost and a 25 percent increase in the share of labor cost in production expenses (U.S. Department of Commerce 1992). Taken together, these changes necessitated new rules and

*Centre for World Food Studies, Vrije Universiteit, Amsterdam, The Netherlands; and Department of Agricultural Economics and Marketing, Rutgers University, New Brunswick, NJ. 
regulations to stop the tendency towards growing corporate farming and public investment to develop labor-saving technological changes.

This study investigates whether or not wages in the Northeast and South regions tend in the long run to be equal relative to the respective regional average wages in 1978. More specifically, an attempt is made to answer three questions: Do wages tend to be equal over time or do they converge? If so, at what rate do they converge? and What will the probability distribution of wages look like in the future? Carried out using county-level data on farm wages, the investigation is performed only for the Northeast and South regions for two reasons. First, since these regions, respectively, fall under the continental and (largely) subtropical ecological zones (Figures $1 \mathrm{a}$ and $1 \mathrm{~b}$ ), differences in convergence across the regions can in part be attributed to differences in ecological conditions. Ecological considerations are implicit in our analysis of wage movements. Second, the regions have nonoverlapping harvest periods: labor demand in the South is generally at a low in August, while Northeast labor demand is near its peak in September. Thus, migrant workers have a chance to move into regions where labor is scarce. Of the migrants in the Northeast in September, 5 percent come from California, 13 percent from within the region, 16 percent from the South, and 66 percent from outside the U.S. (U.S. Department of Labor 1994). This sequentiality in harvest periods considerably helps purify variability in wages from the pressure of regional competition for seasonal workers, makes it largely a within-region issue, and hence allows regional labor market equilibrium mechanisms to work better.

Markov chains are applied, allowing for the integration of the transition information in the cross section data with the steady state information in the time series data. ${ }^{2}$ This is accomplished by estimating a Markov transition function for the data and then by inferring the time-invariant.distribution of the cross section. The contributions of this study to the literature are twofold. First, to the best of our knowledge, the study is the first of its kind, examining convergence of farm wages in the U.S. Second, it brings to the fore a nonparametric method that is useful in projecting the future distributions highly desirable to policy makers.

The remainder of this paper is organized as follows. Section 2 describes Markov chains and states a theorem that guarantees the existence and uniqueness of time-invariant probability distribution. Data, variables, and grouping of counties on the basis of their geographical proximity are all described in Section 3. Section 4 includes the main findings from the Markov chain analysis. Finally, Section 5 elaborates on the policy implications of the findings for U.S. agriculture. Furthermore, the Appendix outlines the $\chi^{2}$ test statistics for the two assumptions of Markov chains.

\section{MARKOV CHAINS}

Consider a stochastic process $\left\{\chi_{t}, t=0,1,2, \ldots\right\}$ that takes on a finite, or countable, number of possible values. Unless otherwise mentioned, this set of

${ }^{2}$ Markov chains were applied by Quah (1993) to analyze convergence of cross-country growth rates and by Robertson (1995) to investigate convergence of bank size. 
FIGURE 1A

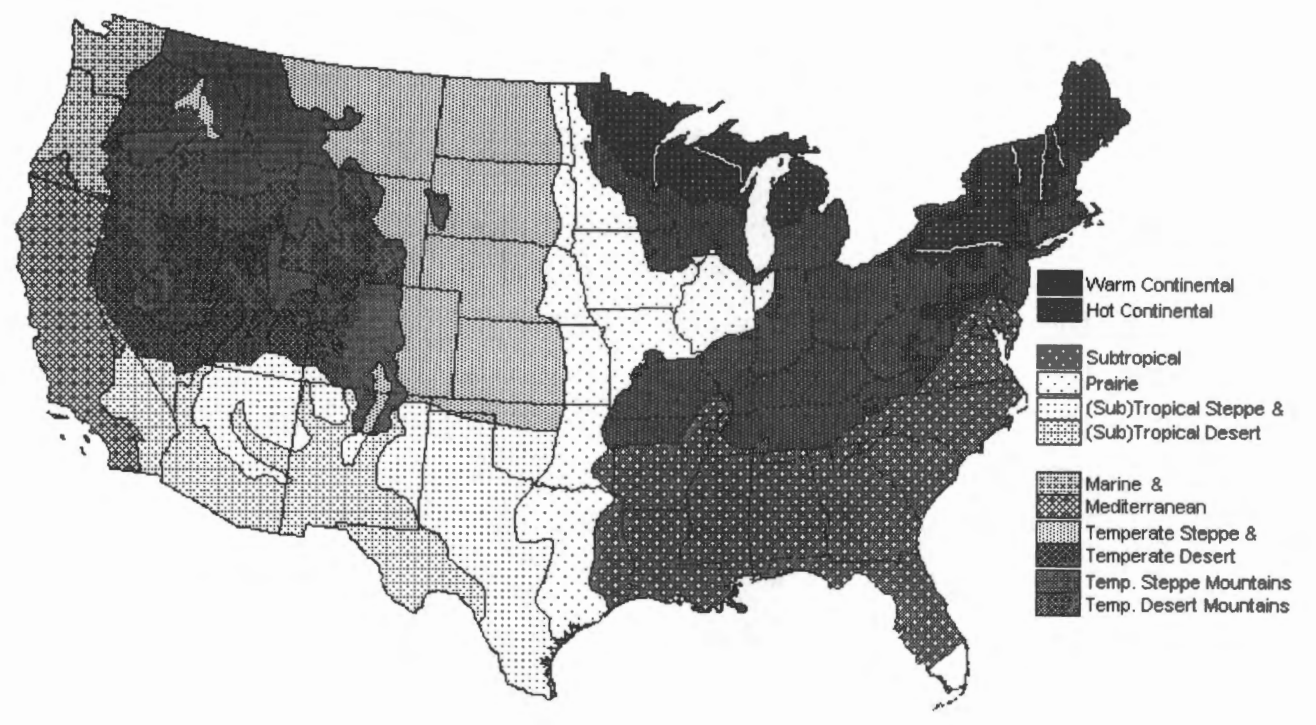

FIGURE 1B

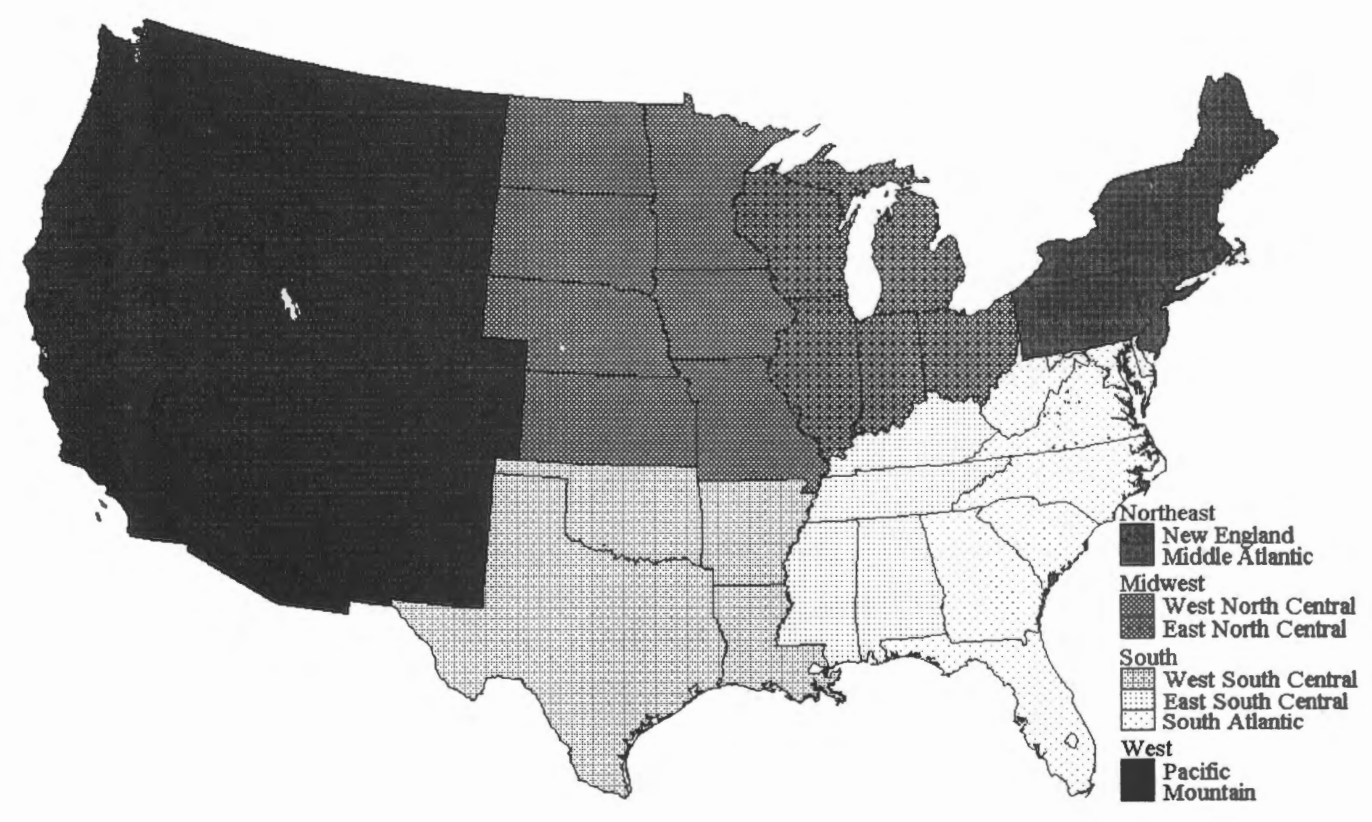

${ }^{1}$ Map is based on Bailey (1996). The authors would like to thank Peter Albersen for his help in preparing the U.S. maps. 
possible values of the process will be denoted by the set of nonnegative integers $\{0,1,2, \ldots\}$. If $X_{t}=i$, then the process is said to be in state $i$ at time $t$.

Assumption 1 (time-stationary transition probabilities). Whenever the process is in state $i$, there is a fixed probability $p_{i j}$ that it will next be in state $j$, that is,

$$
p\left\{X_{t+1}=j \mid X_{t}=i, X_{t-1}=i_{t-1}, \ldots, X_{1}=i_{1}, X_{0}=i_{0}\right\}=p_{i j}
$$

for all states $i_{0}, i_{1}, \ldots, i_{t-1}, i, j$, and $t \geq 0$. Such a stochastic process is known as a Markov chain. Assumption 1 may be interpreted as stating that, for a Markov chain, the conditional distribution of any future state $X_{t+1}$, given the past states $X_{0}$, $X_{1}, \ldots, X_{t+1}$ and the present state $X_{t}$ is independent of the past states and depends only on the present state. The value $\mathrm{p}_{\mathrm{ij}}$ stands for the probability that the process will, when in state $i$, next make a transition into state $j$. Since the probabilities are nonnegative and since the process must make a transition into some state, we have $\sum_{j=0}^{\infty} p_{i j}=1$ for $i=0,1, \ldots$ and $p_{i j} \geq 0$ for $i, j \geq 0$.

Assumption 2 (a first-order Markov chain). The stochastic process follows a first-order chain written as

$$
X_{t+1}=P X_{t}
$$

where $P=\left(p_{i j}\right)$. That is, the probability of a county being in a particular state at time $(t+1)$ is solely a function of its state at time $t$. A second-order chain can similarly be defined as one in which the probability of a county being in a particular state at time $(t+1)$ only depends on that county's states at times $(t-1)$ and $t .^{3}$

If Assumptions 1 and 2 are satisfied, then one can calculate the timestationary transition probabilities as $\mathrm{p}_{\mathrm{ij}}=\left(\frac{\mathrm{n}_{\mathrm{ij}}}{\mathrm{n}_{\mathrm{i}}}\right)$, which is the solution to the following maximization problem:

$$
\operatorname{Max} \prod_{i, j} p_{i j}^{n_{i j}} \text { subject to } \sum_{j=1}^{m} p_{i j}=1 \text { for } i=0,1,2, \ldots, m \text { and } p_{i j} \geq 0 \text {. }
$$

The term $n_{i j}^{t}$ is the number of counties moving from state $i$ at time $(t-1)$ to state $j$ at time $t ; n_{i j}=\sum_{t=1}^{T} n_{i j}^{t}$ is the total number of counties moving from state $i$ to state $j$ over $t=1,2, \ldots, T$; and $n_{i}=\sum_{j=1}^{m} n_{i j}$ is the total number of counties that were in state $\mathrm{i}$ over $\mathrm{t}=0,1, \ldots, \mathrm{T}$ and $\mathrm{i}=\mathrm{j}=1, \ldots, \mathrm{m}$. The $\mathrm{s}$ - step - ahead distribution should evolve as $X_{t+s}=[P]^{s} X_{t}$. The time-invariant distribution $p$ of the stochastic process is obtained as $[\mathrm{P}]^{\mathrm{s}} \rightarrow \pi$ when $\mathrm{s} \rightarrow \infty$. This distribution is one in which the elements of $\mathrm{P}$ no longer change from one period to the next, although counties may continue to alter their states over time.

${ }^{3}$ See the Appendix for testing procedures for the two assumptions. 
Existence and uniqueness of the time-invariant distribution, $\pi$. The presence of the invariant distribution guarantees that the process is independent of initial classification of observations. Provided below are several definitions and a theorem, adopted from Hoel, Port, and Stone (1987), which are used to prove the existence and uniqueness of $\pi$.

Definition 1. Class $i$ is said to have period $d$ if $p_{i j}^{n}=0$ whenever $n$ is not divisible by $d$, and $d$ is the largest integer with this property. For instance, starting in $i$, it may be possible for the process to enter class $i$ only at times $2,4,6,8, \ldots$, in which case class $i$ has period 2 .

Definition 2. A class with period 1 is said to be aperiodic.

Definition 3. Class $j$ is said to be accessible from class $i$ if $p_{i j}^{n}>0$ for some $n \geq 0$.

Definition 4. Two classes $i$ and $j$ that are accessible to each other are said to communicate.

Definition 5. For any class i we let $f_{i}$ denote the probability that, starting in class $i$, the process will ever reenter class $i$. Class $i$ is said to be recurrent if $f_{i}=1$ and transient if $f_{i}<1$. Class $i$ is recurrent if $\sum_{n=1}^{\infty} p_{i i}^{n}=\infty$ and transient if $\sum_{\mathrm{n}=1}^{\infty} \mathrm{p}_{\mathrm{ii}}^{\mathrm{n}}<\infty$.

Definition 6. A Markov chain is said to be irreducible if there is only one grouping of classes; that is, if all classes communicate with each other.

Definition 7. If a class $i$ is recurrent, then it is said to be positive recurrent if, starting in $i$, the expected time until the process returns to class $i$ is finite. Positive recurrent, aperiodic classes are called ergodic.

Theorem 8. For an irreducible ergodic Markov chain, $\lim _{n \rightarrow \infty} p_{i j}^{n}$ exists and is independent of $i$. Furthermore, letting $\pi_{j}=\lim _{n \rightarrow \infty} p_{i j}^{n}, j \geq 0$ then $\pi_{j}$ is the unique nonnegative solution of

$$
\pi_{\mathrm{j}}=\sum_{\mathrm{i}=0}^{\infty} \pi_{\mathrm{i}} \mathrm{p}_{\mathrm{ij}}, \mathrm{j} \geq 0 \text { and } \sum_{\mathrm{j}=0}^{\infty} \pi_{\mathrm{j}}=1 .
$$

\section{DATA AND VARIABLES}

Data employed in this study were obtained from the Census of Agriculture performed at five-year intervals (U.S. Department of Commerce 1992). The data set comprises a separate cross section of 3,130 counties for each year: 1978, 1982, 1987, and 1992. Although information is collected at the farm level, it is translated into county-level information and thus, each county being a unit of observation, is represented by county averages of the variables of interest. 
In order to calculate the variable of interest, county-level real farm wages, two variables were obtained from the Census. The first is the cost of hired farm/ranch labor, $\mathrm{C}_{\mathrm{c}, \mathrm{t}}$ which includes gross salaries and wages, commissions, dismissal pay, vacation pay, and bonuses paid to hired workers, family members, hired managers, administrative and clerical employees, and salaried corporate officers; and supplemental cost for benefits, such as employer's social security contributions, unemployment compensation, workmen's compensation insurance, life and medical insurance, and pension plans. The second is the number of hired farm/ranch workers, $\mathrm{N}_{\mathrm{c}, t^{\prime}}$ which includes paid family members, hired bookkeepers, office workers, and maintenance workers, if their work is primarily associated with agricultural production. It also includes any short-term or temporary workers who may have worked only a few days, but does not include contract labor or custom workers. Consumer price index, $\mathrm{p}_{\mathrm{t}}$, with $1990=100, \mathrm{p}_{1978}=49.9$, $\mathrm{p}_{1982}=73.9, \mathrm{p}_{1987}=87$, and $\mathrm{p}_{1992}=107.4$, is used to deflate the nominal farm wages (International Monetary Fund 1998). Real farm wages per worker in county c at time $t$ are computed as $w_{c, t}=w_{c, t}=\frac{\left(C_{c, t} / N_{c, t}\right)}{p_{t}}$. Denote by $w_{c, t}^{r}$ the time $t$ real farm wage prevailing in county c-region $r$ and calculate the regional average wage as $\bar{w}_{t}^{r}=\left(\frac{1}{n_{r}}\right) \sum_{c=1}^{n_{r}} w_{c, t}^{r}$, where $n_{r}$ is the number of counties in region $r$. Define county $c^{\prime}$ s odds ratio at time $t$ as $F_{c, t}^{r}=\left(w_{c, t}^{r} / \bar{w}_{t}^{r}\right)$.

The number of states (or intervals) in a transition matrix is determined by applying Cochran's (1966) variance minimization rule. First, $\mathrm{F}_{\mathrm{c}, 1978}^{\mathrm{r}}$ is calculated for the initial period, 1978, sorted in an ascending order, and finally divided into intervals in such a way that each interval has minimum variance. Simply looking at the sorted data $\mathrm{F}_{\mathrm{c}, 1978}^{\mathrm{r}}$, we pick jump points in this monotonically increasing sequence as cutoff points. With this procedure, we identify the following five states: for given $r$, State $1=\#\left\{\mathrm{~F}_{c, t}^{\mathrm{r}} \in[0,0.49]\right\}$, State $2=\#\left\{\mathrm{~F}_{c, t}^{\mathrm{r}} \in[0.50,0.99]\right\}$, State $3=\#\left\{F_{c, t}^{r} \in[1.00,1.49]\right\}$, State $4=\#\left\{F_{c, t}^{r} \in[0.50,1.99]\right\}$, and State $5=\#\left\{F_{c, t}^{r}>1.99\right\}$, where the sign \# denotes the number of counties in the respective set.

\section{TRANSITION DYNAMICS}

Based on cross section, time series information, the two transition probability matrices (Tables 1 and 2), one for the Northeast region and one for the South region, describe how the long-run distribution for wages will evolve. In the following paragraphs, the conditions for an irreducible, ergodic Markov chain are discussed only in the context of the transition probability matrix for the 
Northeast region. Similar interpretations are also applied to the transition matrix for the South.

TABLE 1

Transition Matrix for the Northeast $(P)$

\begin{tabular}{lccccccc}
\hline & & \multicolumn{7}{c}{$(\mathrm{t}+1)$} & \\
& States & 1 & 2 & 3 & 4 & 5 & $\mathrm{~N}$ \\
\hline & 1 & 0.50 & 0.46 & 0.04 & & & 20 \\
$(\mathrm{t})$ & 2 & 0.05 & 0.74 & 0.20 & 0.01 & & 214 \\
& 3 & & 0.37 & 0.51 & 0.10 & 0.02 & 115 \\
& 4 & & 0.10 & 0.30 & 0.40 & 0.20 & 29 \\
& 5 & & 0.06 & 0.28 & 0.33 & 0.33 & 12 \\
\hline T-invariant & & 0.06 & 0.55 & 0.29 & 0.07 & 0.03 & 390 \\
Eigenvalues & & 1.00 & 0.66 & 0.46 & 0.26 & 0.10 & \\
\hline
\end{tabular}

The probabilities in the first row of the transition matrix for the Northeast region are $p_{11}=0.50, p_{12}=0.46$, and $p_{13}=0.04$. Of the entire sample of 390 , a total of 20 counties over the period 1978-92 fell in State 1 . Of these 20 counties, 50 percent $\left(p_{11}\right)$ remained in that same state; 46 percent $\left(p_{12}\right)$ moved into State 2; and 4 percent $\left(p_{13}\right)$ moved into State 3 in the following period.

State 2 is accessible from State 1 since $p_{12}$ is positive (0.46). States 1 and 2 are accessible to each other, hence they are said to communicate, and it is denoted by $1 \longleftrightarrow 2$. In fact, the case in which all the five states communicate implies that all of the states are in the same class. The Markov chain is then irreducible since there is only one class. For the Northeast, the Markov chain is irreducible, since it is possible to go from State 1 to 5 through the path $1 \stackrel{0.46}{\longleftrightarrow} 2 \stackrel{0.20}{\longleftrightarrow} 3 \stackrel{0.10}{\longleftrightarrow} 4 \stackrel{0.20}{\longleftrightarrow} 5$. In other words, one way of getting from State 1 to 5 is to go from State 1 to 2 (with probability $\mathrm{p}_{12}=0.46$ ), then go from State 2 to 3 (with probability $\mathrm{p}_{23}=0.20$ ), ..., and finally go from State 4 to 5 (with probability $\mathrm{p}_{45}=0.20$ ).

Persistence is measured with the probabilities in the diagonal elements of a transition matrix; large values suggest high persistence, low values suggest low persistence. The dominant feature in the transition matrix for the Northeast is high persistence among those counties in State 2 and low persistence in States 5 and 4 . This is implied by the corresponding diagonal entries: $0.74,0.33$, and 0.40 . A close look at the off-diagonal elements also shows a pattern of movements: one in which counties tend to move towards States 2 and 3. This is a pattern in which a large majority of farms moves towards a level little less than the regional 1978 average wage. Consider, for example, 20 counties in State 1 . Of these, 46 percent tend to move into State 2 and only 4 percent into State 3 in the following period. Likewise, of 29 counties in State 4, 30 percent tend to move into State 3, while only 20 percent move into State 5. One can also calculate a measure of mobility $\mu$ as $\mu(P)=(m-\operatorname{Trace}(\mathrm{P})) /(\mathrm{m}-1)=(5-2.48) / 4=0.63$, where the chain $\mathrm{P}$ is of dimension $\mathrm{m}=5 .{ }^{4}$ The lower is $\mu$, the lower the mobility (or higher the persistence) there is in the county-level wages (Quah 1993).

${ }^{4}$ Trace $(P)$ is defined as the sum of diagonal elements in $P$. 
The time-invariant distribution characterizes the limiting behavior of countylevel wages as the number of iterations of $P$ goes to $\infty$. Nothing enforces existence or uniqueness of this distribution. That precisely one such distribution was found is a consequence of $\mathrm{P}$ at hand. Note that the invariant distribution is a projection of what is likely to happen in the future, provided that policies remain unchanged for a sufficiently long period of time and that no unforeseen events occur. The invariant distribution for the Northeast is $\left(\pi_{1}=0.06, \pi_{2}=0.55, \pi_{3}=0.29, \pi_{4}=0.07\right.$, $\pi_{5}=0.03$ ) (Figure 2). Everything else constant, this distribution states that in the final period, States 2 and 3 should include 84 percent $\left(=\pi_{2}+\pi_{3}\right)$ of 390 counties in the Northeast. This establishes a right-skewed distribution in which there is a peak at State 2, suggesting that at the limit the majority of counties would move away from the regional average wage in 1978 and that wages would converge to a level lower than this average. Since there is only one peak to emerge, polarization does not take place in the Northeast. If, however, there had been two peaks, one on the lower tail and the other on the upper tail of the invariant distribution, then one would have claimed two peaks, implying polarization, or the coexistence of highand low-wage counties in the future.

FIGURE 2

Distribution of Farm Wages

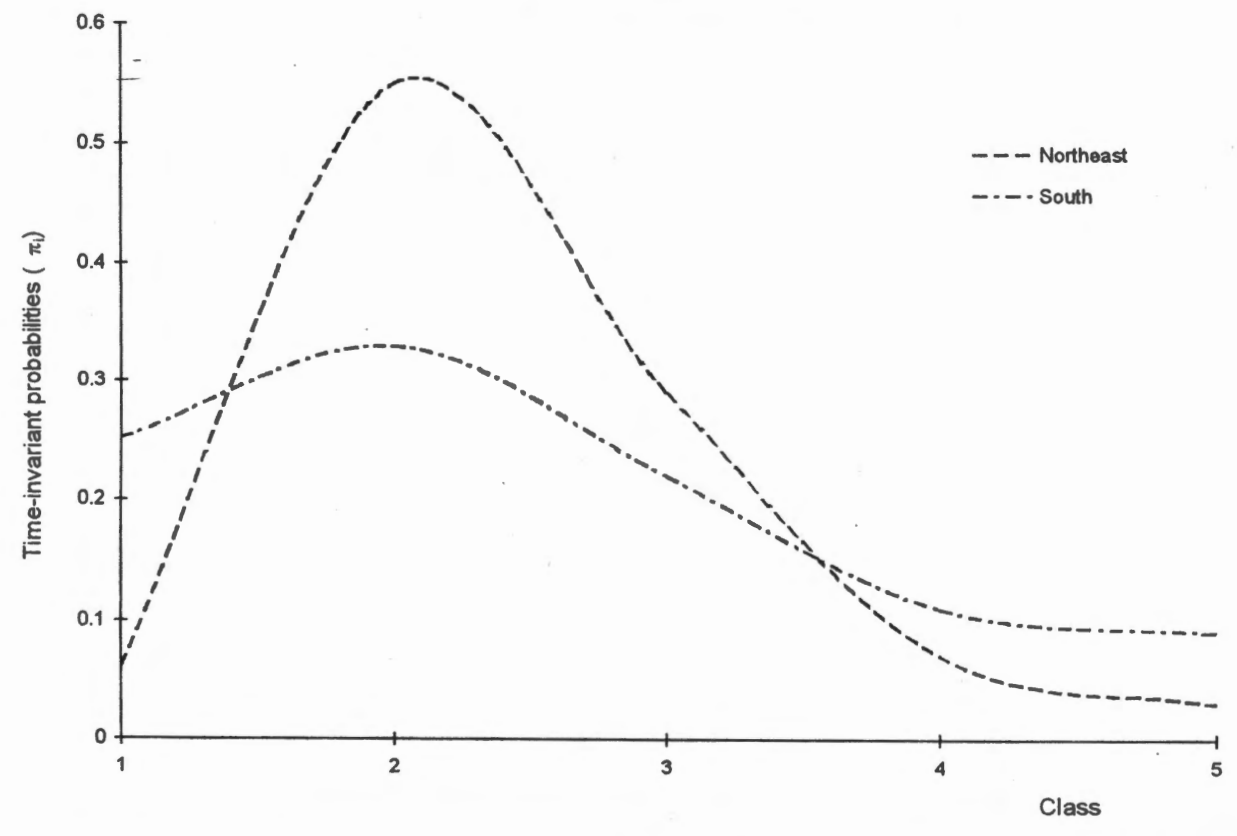

To detect a common tendency, if there is any, in agricultural labor markets in the Northeast, the time-invariant and actual terminal period distributions of wages are compared. With the time-invariant distribution $\left(\pi_{1}=0.06, \pi_{2}=0.55\right.$, $\left.\pi_{3}=0.29, \pi_{4}=0.07, \pi_{5}=0.03\right)$, and the actual terminal period distribution $\left(\pi_{1}=0.05\right.$, $\pi_{2}=0.55, \pi_{3}=0.30, \pi_{4}=0.07, \pi_{5}=0.03$ ), which are almost identical, the Northeast reveals a tendency in labor markets towards an equilibrium wage rate that is likely to be lower than the 1978 regional average wage. 
A bell-shaped distribution $\pi$ should imply convergence to the regional average, a left- (right-) skewed distribution should imply convergence to a level higher (lower) than the regional average, and a bimodal distribution should imply polarization. The speed of convergence, denoted by $\lambda$ and measured by the second largest eigenvalue of the chain $\mathrm{P}$, is the rate at which $\mathrm{P}$ converges to the time-invariant distribution. The speed for the Northeast is $0.66 .^{5}$

Assumption 1 is tested by using a $X^{2}$ statistic under the null hypothesis that the Markov chain is time-stationary. The null is accepted at the 0.05 level, since the calculated $\chi^{2}$ statistic $<$ the table $\chi_{m(m-1)(T-1)}^{2}$, where $m=5$ and $T=3$. Had it been nonstationary, the transition probability matrix for each period would have been examined separately.

TABLE 2

Transition Matrix for the South $(\mathrm{P})$

\begin{tabular}{lccccccc}
\hline & & \multicolumn{7}{c}{$(\mathrm{t}+1)$} & & \\
& States & 1 & 2 & 3 & 4 & 5 & $\mathrm{~N}$ \\
\hline & 1 & 0.77 & 0.20 & 0.03 & & & 685 \\
& 2 & 0.15 & 0.59 & 0.21 & 0.03 & 0.02 & 892 \\
$(\mathrm{t})$ & 3 & 0.04 & 0.30 & 0.44 & 0.17 & 0.05 & 509 \\
& 4 & 0.01 & 0.13 & 0.13 & 0.33 & 0.20 & 289 \\
& 5 & & 0.03 & 0.12 & 0.28 & 0.57 & 238 \\
\hline T-invariant & & 0.25 & 0.33 & 0.22 & 0.11 & 0.09 & 2,622 \\
Eigenvalues & & 1.00 & 0.79 & 0.55 & 0.29 & 0.08 & \\
\hline
\end{tabular}

The above interpretations apply to the transition matrix for the South region as well. $\mathrm{A} X^{2}$ test validates the assumption that the process is time-invariant. Since the time horizon of the actual data is not long enough to formulate a second-order chain, the process is assumed, without testing, to be of first order. The mobility measure $\mu$ is equal to 0.58 for the South, implying that counties in the South that are represented by their average farm wages move from one state to another at a relatively slower speed than that taking place in the Northeast. The South has higher persistence than the Northeast, and consistent with it is a higher rate of convergence, $\lambda=0.79$.

The time-invariant probabilities indicate that, in the final period, wages are expected to be even smaller than that those in the Northeast, with 80 percent $\left(=\pi_{1}+\pi_{2}+\pi_{3}\right)$ of the counties in the South clustering around States 1-3 (see Figure 2). A comparison of the time-invariant distribution, $\left(\pi_{1}=0.25, \pi_{2}=0.33, \pi_{3}=0.22\right.$, $\left.\pi_{4}=0.11, \pi_{5}=0.09\right)$ with the actual terminal period distribution $\left(\pi_{1}=0.26, \pi_{2}=0.34\right.$, $\pi_{3}=0.20, \pi_{4}=0.11, \pi_{5}=0.09$ ) supports that a much stronger tendency has occurred in the South towards a wage rate lower than the 1978 regional average wage.

\section{MAIN FINDINGS AND POLICY IMPLICATIONS}

Advocates of farm operators argue that temporary foreign worker programs and tolerant entry programs at U.S. borders are necessary to ensure an affordable work force during critical periods. On the contrary, farm workers' organizations

${ }^{5}$ Since the time-invariant distribution is computed as the left eigenvector corresponding to the (isolated) unit eigenvalue, which is the largest eigenvalue of the kernel $P$, the second largest eigenvalue should measure the speed of convergence. 
often contend that such policies create an oversupply of workers and depress wages. In this study we confined ourselves to the projection of the long-run distribution of real farm wages in the Northeast and South regions over the period 1978-92, and indirectly tested whether or not wages tend to depress in the future. The main result supports the farm workers' claim that wages in both regions are more likely to decline relative to the respective regional averages in 1978. Marston (1985) and Duffield and Coltrane (1992) found that labor supply and demand are responsive to market signals, and therefore equilibrium conditions should prevail in the farm labor market. Their finding and ours together suggest that the oversupply of labor, which might manifest itself in the form of low wages, can be considered as a symptom of a healthy labor market responding to market signals.

More specific findings are threefold. First, in the future wages are expected to depress in both the Northeast and the South, as implied by the regional timeinvariant distributions that are skewed right (Figure 2). Second, with $\mu=0.58$, the lowest mobility (or the highest persistence) is observed among counties in the South; and with $\mu=0.63$, the highest mobility (or the lowest persistence) is observed in the Northeast. Consistent with this are the fastest $(\lambda=0.79)$ and slowest $(\lambda=0.66)$ speeds of convergence in the South and Northeast, respectively. When taken together, these measures provide evidence that agricultural labor markets will relatively speaking be stable in the South. Third, the convergence of wages to lower-than-regional average is stronger in the Northeast. This is reflected by the prediction that as much as 61 percent of the counties in this region are expected in the long run to be in either State 1 or 2, while the same figure is 58 percent for the South (Figure 2).

These findings do hold implications for labor migration and technological change. Most of migrant farm workers move into areas of vegetables and fruits/nuts farming, while a less significant number go into areas of horticulture and crop farming. Over the period 1989-91, the proportion of workers who migrated to vegetables, fruits/nuts, horticulture, and crop farming areas was 52, 51, 29, and 20 percent, respectively (U.S. Department of Labor 1994). In the Northeast, where farming is largely of vegetables, fruits, and horticultural products, wages tend to be higher than those in the South due to regional competition for these workers. The Northeast obtains workers from California (5 percent), the South (16 percent), outside the U.S. (66 percent), and within the region (13 percent) during peak labor requirements in September. Contrary to this, the South obtains 35 percent of its migrant labor from within the region, 57 percent from outside the U.S., 6 percent from the Northeast, and 2 percent from California. Even at off-peak periods, migrants comprise 46 percent of the South's farm labor force. This ready supply of labor should lower the pressure on wages in the South. In short, policies that create an oversupply of farm workers will especially depress wages in the Northeast where these workers are most demanded.

With respect to technological change, there is a puzzle to solve. Considerable microevidence finds a positive relationship between the introduction of new technologies and rising wage inequality (i.e., divergence of wages) because, as 
Berman, Bound, and Griliches (1994) document, industries that invest more in research and development tend to pay a higher premium for skill. On the contrary, recent macroeconomic evidence suggests that technological change and wage inequality have been negatively correlated over time (Blackburn, Bloom, and Freeman 1990-91). In the context of our study, conjecturing a decline in future farm wages, it is rational to expect for future technology to be labor saving (or labor augmenting), provided that no government intervention is made to reverse it (Ruttan and Hayami 1978). Therefore, in the preparation of a new farm bill, special considerations should be given to the design of programs or institutions that might directly or indirectly affect the path of technological change. Important to mention in this respect are training programs for farmers' acquisition of laboraugmenting technical skills.

The government can indirectly influence wages by investing in the development of an enabling environment for farmers to operate as profit-maximizing agents, whose production decisions are not constrained by direct government payments and by subsidies that are tied to farmers' production decisions. For wages to be determined efficiently, a new farm bill should remove government payments and subsidies. Everything else equal, a decline in farm subsidies results in a decline in farm income. To the extent that farmers have perceived farm commodity payments as a permanent part of farm income, this decline will be indirectly reflected in farm labor demand and wages. Moreover, the loss of farm subsidies could increase the variability in farm income, making agricultural production more risky. Secondly, the new farm bill should no longer use commodity programs to control output. Under previous farm legislation, annual set-aside programs were an important policy tool for controlling U.S. production of major program crops. To receive federal subsidies, farmers had to agree to set-asides of a portion of their acres. Under the new regime, such programs should be cautiously formulated so that producers freely respond to market prices.

To date, research has evolved around the impacts on economywide wage inequalities of unionization, trade, and technical change (DiNardo, Fortin, and Lemieux 1996; Card 1996; Chaykowski and Slotsve 1996; Fortin and Lemieux 1997; Murphy and Welch 1991; Bound and Johnson 1992; Juhn, Murphy, and Pierce 1993; and Bhagwati and Kosters 1994). Future research should concentrate on the quantification of similar impacts at a sectoral level, aiming to extend the methodology that was employed in this study.

\section{APPENDIX}

\section{HYPOTHESIS TESTING}

Here we present hypothesis testing procedures, adopted from Anderson and Goodman (1957) and Goodman (1962), to investigate whether or not the transition probability matrices at hand are time-stationary and follow a first-order process. For illustrative purposes, the following contingency table will be referred to throughout this Appendix: 


$\mathrm{A}(\mathrm{t})=$\begin{tabular}{|l|l|l|l|}
\hline States & 1 & 2 & Total \\
\hline 1 & $\mathrm{n}_{11}^{\mathrm{t}}$ & $\mathrm{n}_{12}^{\mathrm{t}}$ & $\mathrm{n}_{1 .}^{\mathrm{t}}$ \\
2 & $\mathrm{n}_{21}^{\mathrm{t}}$ & $\mathrm{n}_{22}^{\mathrm{t}}$ & $\mathrm{n}_{2 .}^{\mathrm{t}}$ \\
\hline Total & $\mathrm{n}_{.1}^{\mathrm{t}}$ & $\mathrm{n}_{.2}^{\mathrm{t}}$ & $\mathrm{n}^{\mathrm{t}}$ \\
\hline
\end{tabular} and $\mathrm{Z}_{\mathrm{i}}=$\begin{tabular}{|l|l|l|}
$\mathrm{t} / \mathrm{j}$ & $\mathrm{j}=1$ & $\mathrm{j}=2$ \\
\hline $\mathrm{t}=1$ & $\hat{\mathrm{p}}_{\mathrm{i} 1}^{1}$ & $\hat{\mathrm{p}}_{\mathrm{i} 2}^{1}$ \\
$\mathrm{t}=2$ & $\hat{\mathrm{p}}_{\mathrm{i} 1}^{2}$ & $\hat{\mathrm{p}}_{\mathrm{i} 2}^{2}$ \\
$\mathrm{t}=3$ & $\hat{\mathrm{p}}_{\mathrm{i} 1}^{3}$ & $\hat{\mathrm{p}}_{\mathrm{i} 2}^{3}$ \\
\hline
\end{tabular}

If $\mathrm{T}=3$, then we will have three contingency tables, $\mathrm{A}(\mathrm{t})$ for $\mathrm{t}=1,2,3$, given two states $i=j=1$, 2. In this example, $n_{i j}=\sum_{t=1}^{3} n_{i j}^{t}$ and $n_{i}=\sum_{i=1}^{2} n_{i j}=\sum_{t=1}^{3} n_{i}^{t}$.

Assumption 1. The transition probabilities are time-stationary. Here the null hypothesis is $\mathrm{H}_{0}: \mathrm{p}_{\mathrm{ij}}^{\mathrm{t}}=\hat{\mathrm{p}}_{\mathrm{ij}}$ for all $\mathrm{t}$, and an alternative to this assumption is that the transition probability depends on $t, H_{1}: p_{i j}^{t}=\hat{p}_{i j}^{t}$, where $\hat{p}_{i j}^{t}=\left(\frac{n_{i j}^{t}}{n_{i}^{t-1}}\right)$ is the estimate of the transition probability for time t. Under these hypotheses, the likelihood ratio is of the form $\lambda=\Pi_{t} \Pi_{i, j}\left[\frac{\hat{p}_{i j}}{\hat{p}_{i j}^{t}}\right]^{n_{i j}^{t}}$, where $\Pi_{t=1}^{T} \Pi_{i, j} \hat{p}_{i j}^{n_{i j}^{t}}$ holds under $H_{0}$ and $\Pi_{\mathrm{t}=1}^{\mathrm{T}} \Pi_{\mathrm{i}, \mathrm{j}}\left(\hat{\mathrm{p}}_{\mathrm{ij}}^{\mathrm{t}}\right)^{\mathrm{n}_{\mathrm{i}}^{\mathrm{t}}}$ holds under $\mathrm{H}_{1}$. And -2log $\lambda$ is distributed as $\chi_{(\mathrm{T}-1)[\mathrm{m}(\mathrm{m}-1)]}^{2}$ when $\mathrm{H}_{0}$ is true. It should be noted that the likelihood ratio resembles likelihood ratios obtained for standard tests of homogeneity in contingency table $A(t)$. The null hypothesis states that the random variables represented by the $T$ rows in $Z_{i}$ have the same distribution. In order to test it, we calculate $\chi_{i}^{2}=\sum_{i, j} n_{i}^{t-1}\left(\hat{p}_{i j}^{t}-\hat{p}_{i j}\right)^{2} / \hat{p}_{i j}$. If $\mathrm{H}_{0}$ is true, $\chi_{\mathrm{i}}^{2}$ has the limiting distribution with $(\mathrm{m}-1)(\mathrm{T}-1)$ degrees of freedom, the set of $\chi_{\mathrm{i}}^{2 \text { 's }}$ is asymptotically independent, and the sum $\chi^{2}=\sum_{\mathrm{i}=1}^{2} \chi_{\mathrm{i}}^{2}=\sum_{\mathrm{i}} \sum_{\mathrm{t}, \mathrm{j}} \mathrm{n}_{\mathrm{i}}^{\mathrm{t}-1}\left(\hat{\mathrm{p}}_{\mathrm{ij}}^{\mathrm{t}}-\hat{\mathrm{p}}_{\mathrm{ij}}\right)^{2} / \hat{\mathrm{p}}_{\mathrm{ij}}$ has the usual limiting distribution with $(T-1)[m(m-1)]$ degrees of freedom.

Another way of testing the same hypothesis is to calculate $\lambda_{\mathrm{i}}=\prod_{\mathrm{t}, \mathrm{j}}\left[\frac{\hat{\mathrm{p}}_{\mathrm{ij}}}{\hat{\mathrm{p}}_{\mathrm{ij}}^{t}}\right]^{\mathrm{n}_{\mathrm{ij}}^{\mathrm{t}}}$ for $\mathrm{i}=1,2$ by using $\mathrm{Z}_{\mathrm{i}}$. The asymptotic distribution of $-2 \log \lambda_{\mathrm{i}}$ is $\chi_{\mathrm{i}}^{2}$ with $(\mathrm{m}-1)(\mathrm{T}-1)$ degrees of freedom. The test criterion based on $\lambda$ can then be written as $\sum_{i=1}^{m}-2 \log \lambda_{i}=-2 \log \lambda$. 
Assumption 2. The Markov chain is of a given order. Intuitively speaking, this assumption states that the location of a county at time $(t+1)$ is independent of its location at time $t$. A Markov chain is second order if a county is in class $i$ at time $(t-2)$, in $j$ at time $(t-1)$, and in $k$ at time $t$. Let $p_{i j k}^{t}$ denote the probability that a county follows a second-order chain. Time stationarity then implies $p_{\mathrm{ijk}}^{t}=p_{\mathrm{ijk}}$ for all $t=2, \ldots, T$. A first-order stationary chain is a special case of second-order chain, one for which $\mathrm{p}_{\mathrm{ijk}}^{\mathrm{t}}$ does not depend on $\mathrm{i}$.

Now let $n_{i j k}^{t}$ be the number of counties in class $i$ at $(t-2)$, in class $j$ at $(t-1)$, and in class $k$ at $t$. Let $n_{i j}^{t-1}=\sum_{k} n_{i j k}^{t}$ and $n_{i j k}=\sum_{t=2}^{T} n_{i j k}^{t}$. The maximum likelihood estimate of $p_{i j k}$ for stationary chains is $\hat{p}_{i j k}=\left(n_{i j k} / \sum_{l=1}^{m} n_{i j l}\right)=\left(\sum_{t=2}^{T} n_{i j k}^{t} / \sum_{t=2}^{T} n_{i j}^{t-1}\right)$. The null hypothesis in this case is $H_{0}: p_{1 j k}=p_{2 j k}=\ldots=p_{m j k}=p_{j k}$ for $j, k=1, \ldots, m$. The likelihood ratio test criterion is $\lambda=\prod_{i, j, k=1}^{m}\left\lceil\frac{\hat{p}_{j k}}{\hat{p}_{i i k}}\right]^{n_{i j h}}$, where $\hat{p}_{i j k}=$ $\left(\sum_{\mathrm{i}=1}^{\mathrm{m}} \mathrm{n}_{\mathrm{ijk}} / \sum_{\mathrm{i}=1}^{\mathrm{m}} \sum_{\mathrm{l}=1}^{\mathrm{m}} \mathrm{n}_{\mathrm{ijl}}\right)=\left(\sum_{\mathrm{t}=2}^{\mathrm{T}} \mathrm{n}_{\mathrm{jk}}^{\mathrm{t}} / \sum_{\mathrm{t}=1}^{\mathrm{T}-1} \mathrm{n}_{\mathrm{j}}^{\mathrm{t}}\right)$ is the maximum likelihood estimate of $p_{j k}$. Under the null hypothesis, $-2 \log \lambda$ has an asymptotic $\chi_{m(m-1)^{2}}^{2}$ distribution where $\chi_{\mathrm{j}}^{2}=\sum_{\mathrm{i}, \mathrm{k}} n_{\mathrm{ij}}^{*}\left(\hat{\mathrm{p}}_{\mathrm{ijk}}-\hat{\mathrm{p}}_{\mathrm{jk}}\right)^{2} / \hat{\mathrm{p}}_{\mathrm{jk}}$ and $\mathrm{n}_{\mathrm{ij}}^{*}=\sum_{\mathrm{k}} \mathrm{n}_{\mathrm{ijk}}=\sum_{\mathrm{k}} \sum_{\mathrm{t}=2}^{\mathrm{T}} \mathrm{n}_{\mathrm{ijk}}^{\mathrm{t}}=$ $\sum_{t=2}^{T} n_{i j}^{t-1}=\sum_{t=1}^{T-1} n_{i j}^{t}$ with $(m-1)^{2}$ degrees of freedom. The corresponding test using the likelihood ratio is $\lambda_{j}=\prod_{i, k=1}^{m}\left[\frac{\hat{p}_{j k}}{\hat{p}_{i j k}}\right]^{n_{i j k}}$. The asymptotic distribution of $2 \log 1 \lambda_{j}$ is chi-square with $(m-1)^{2}$ degrees of freedom.

To test the joint hypothesis $\mathrm{H}_{0}: \mathrm{p}_{\mathrm{ijk}}=\mathrm{p}_{\mathrm{jk}}$ for all $\mathrm{i}, \mathrm{j}, \mathrm{k}=1,2, \ldots, \mathrm{m}$, we calculate $\chi^{2}=\sum_{j=1}^{m} \chi_{j}^{2}=\sum_{j, i, k} n_{i j}^{*}\left(\hat{p}_{i j k}-\hat{p}_{j k}\right)^{2} / \hat{p}_{j k}$, which has the limiting distribution with $m(m-1)^{2}$. Similarly, the joint test criterion is $\sum_{j=1}^{m}-2 \log \lambda_{j}=-2 \log \lambda=2 \sum_{j, i, k} n_{i j k}\left[\log \hat{p}_{i j k}-\log \hat{p}_{j k}\right]$.

\section{REFERENCES}

Anderson, W.T., and A.L. Goodman. "Statistical Inference about Markov Chains." The Annals of Mathematical Statistics 28 (1957), 89-110.

Bailey, G.R. Ecosystem Geography. New York: Springer-Verlag, 1996.

Berman, E., J. Bound, and Z. Griliches. "Changes in the Demand for Skilled Labor within U.S. Manufacturing: Evidence from the Annual Survey of Manufacturers." Quarterly Journal of Economics 109 (1994), 367-97. 
Bhagwati, J., and M.H. Kosters (eds.) Trade and Wages: Leveling Wages Down. Washington, D.C.: American Enterprise Institute Press, 1994.

Blackburn, L.M., E.D. Bloom, and B.R. Freeman. "An Era of Falling Earnings and Rising Inequality?" Brookings Review 9 (1990-91), 38-43.

Bound, J., and G. Johnson. "Changes in the Structure of Wages in the 1980s: An Evaluation of Alternative Explanations." American Economic Review 82 (1992), 371-92.

Carayannis, E.G., and R. Mallick. "Regional Income Disparities in Canada: Implications for Theories of Regional Convergence." Review of Regional Studies 26 (1996), 55-74.

Card, D. "The Effect of Unions on the Structure of Wages. A Longitudinal Analysis." Econometrica 64 (1996), 957-79.

Chaykowski, P.R., and A.G. Slotsve. "A Distributional Analysis of Changes in Earnings Inequality among Unionized and Nonunionized Male Workers in the U.S.: 1982-1990." Canadian Journal of Economics 29 (1996), S109-S113. Cochran, W. Sampling Techniques. 2d ed. New York: John Wiley \& Sons, Inc., 1966. DiNardo, J., M.N. Fortin, and T. Lemieux. "Labor Market Institutions and the Distribution of Wages, 1973-1992: A Semiparametric Approach." Econometrica 64 (1996), 1001-44.

Duffield, A.J., and R. Coltrane. "Testing for Disequilibrium in the Hired Farm Labor Market." American Journal of Agricultural Economics 74 (1992), 412-20.

Fortin, M.N., and T. Lemieux. "Institutional Changes and Rising Wage Inequality: Is there a Linkage?" Journal of Economic Perspectives 11 (1997), 75-96.

Goodman, A.L. "Statistical Methods for Analyzing Processes of Change." The American Journal of Sociology 68 (1962), 57-78.

Hoel, P.G., S.C. Port, and C.J. Stone. Introduction to Stochastic Processes. Prospect Heights, IL: Waveland Press, Inc., 1987.

International Monetary Fund. International Financial Statistics. Washington, D.C., 1998. Juhn, C., K. Murphy, and B. Pierce. "Wage Inequality and the Rise in Returns to Skill." Journal of Political Economy 101 (1993), 410-42.

Marston, T.S. "Two Views of the Geographic Distribution of Unemployment." Quarterly Journal of Economics 10 (1985), 57-79.

Murphy, K., and F. Welch. "The Role of International Trade in Wage Differentials." In M. Kosters (ed.) Workers and their Wages: Changing Patterns in the U.S. Washington, D.C.: American Enterprise Institute Press, 1991.

Quah, D. "Empirical Cross-Section Dynamics in Economic Growth." European Economic Review 37 (1993), 426-34.

Robertson, D. "Are Banks Converging to One Size?" Working Paper No. 95-29. Economic Research Division, Federal Reserve Bank of Philadelphia, 1995.

Ruttan, V., and Y. Hayami. Agricultural Development. Baltimore: Johns Hopkins University Press, 1978.

U.S. Department of Commerce. Census of Agriculture 1992. Washington, D.C., 1992.

U.S. Department of Labor. Office of Program Economics. "Migrant Farm Workers:

Pursuing Security in an Unstable Labor Market." Research Report No. 5. Washington, D.C., 1994. 